\title{
Controller Performance Analysis for a Delayed Process Based on Integral Error Performance Indices
}

\author{
DEEKSHA NAITHANI ${ }^{1}$, MAYANK CHATURVEDI ${ }^{1 *}$ and PRADEEP KUMAR JUNEJA ${ }^{2}$ \\ ${ }^{1}$ Department of Electrical Engineering, ${ }^{2}$ Department of Electronics \& Communication Engineering, \\ Graphic Era University, Dehradun, India. \\ *Corresponding author E-mail : mayankchaturvedi.geit@gmail.com
}

http://dx.doi.org/10.13005/ojc/320344

(Received: May 28, 2016; Accepted: June 25, 2016)

\begin{abstract}
In the present work, heat exchanger process is selected for investigation, which can be modelled as first order plus dead time model. PI controllers using various tuning techniques that are Ziegler-Nichols, Shinskey, Skogestad, Liptak and Moros have been designed for the selected process. Important time response characteristics and integral error performance indices viz. ISE, IAE and ITAE are calculated and compared to evaluate controller performance.
\end{abstract}

Keywords: Performance indices, Heat exchanger, dead time, FOPDT.

\section{INTRODUCTION}

In process industries controlling the process is main issue. For the industries it is very important to keep process working properly for optimum results and good quality of product. Most of the industrial processes have inherent dead time and its existence is extremely undesirable in the processes including chemical processes1-4. Dead time also known as delay time and occurs due to delay involved in measurement devices, final control element and human controller and between two consecutive actions of the process 5,6 . The present analysis emphasize on first order plus dead time (FOPDT) process model as they represent a wide class of chemical processes available in chemical industries. The FOPDT process model can be given by the transfer function:

$$
G(s)=\frac{K e-\theta s}{(1+\tau s)}
$$

Where $\mathrm{K}$ is process gain, $\theta$ is dead time and $\tau$ is time constantA heat exchanger process which can be modelled as FOPDT process model is selected for investigation. A chemical process for heating contains a chemical reactor and a heat exchanger system ${ }^{7}$. In literature two assumptions are made regarding this process. First assumption is that a liquid level remains constant. The second 
assumption is heat storage capacity of insulating wall is negligible8.

Proportional Integral controllers are widely used in process industries because of ease and simplicity in tuning9. PI controller used to eliminate steady state error. It is generally used where speed of response is not an issue10. The proportional action gives change in input proportional to the error. The integral action gives integral of error and main purpose is to eliminate offset. The proportional controller then takes the appropriate action 11, 12. In general PI controller can be given as

$$
\mathrm{Gc}(\mathrm{s})=\mathrm{Kc}[1+\tau \mid \mathrm{s}]
$$

Performance indices are the quantitative measurement of the system and articulates about the systems optimality. In other words it make a distinction between optimum and non-optimum systems. Systems parameters are so adjusted that index should reach an extreme value probably the minimum value for best performance of the system 13. Steady state and dynamic time response characteristics also signifies the performance of the controller and hence the overall performance of the system.

\section{METHODOLOGY}

In present analysis a heat exchanger which can be modelled as FOPDT process model is selected. After selecting pertinent FOPDT process model, controller parameters are calculated to design PI controller using various tuning techniques such as Ziegler- Nichols, Liptak, Moros, Shinskey and Skogestad. The PI controller is then implemented in the system to control the process, in a closed loop with unity feedback. Integral Error based performance indices viz. ISE, ITAE and IAE performance indices are calculated along with steady state and dynamic time response characteristics using step input.

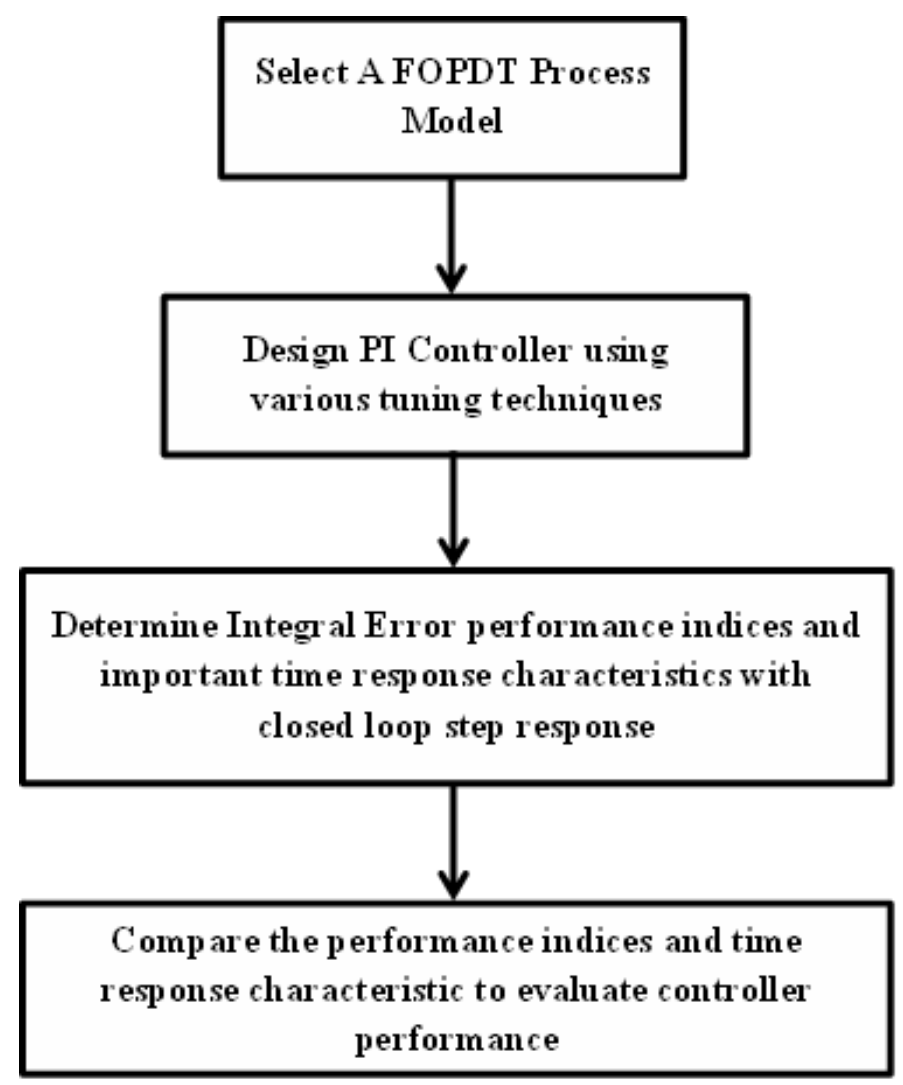

Fig. 1: Flowchart for organized analysis 


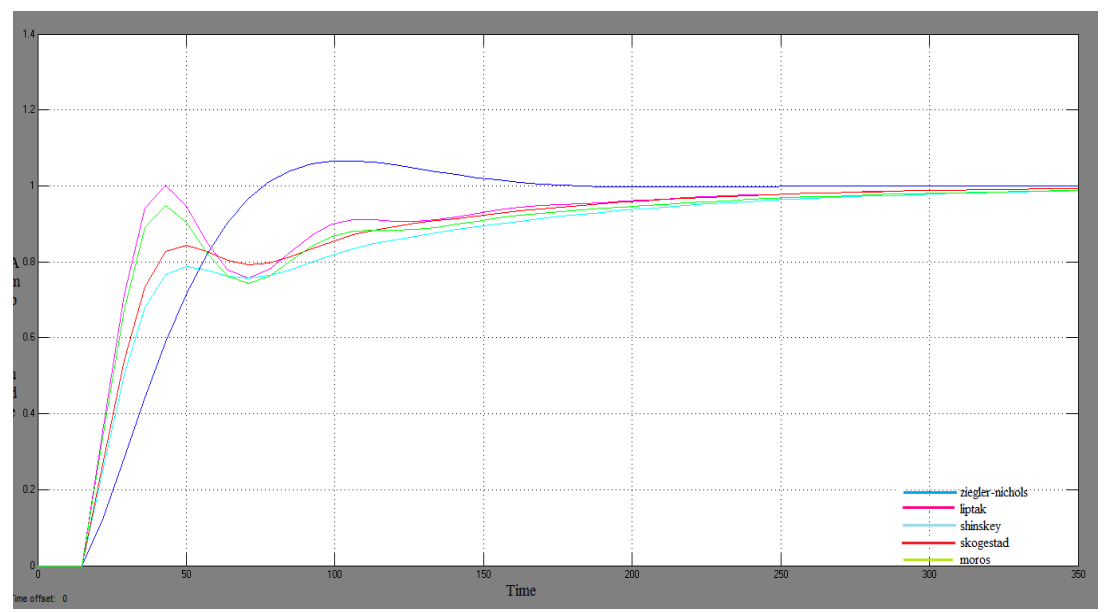

Fig. 2: Comparison of closed loop step response for PI controllers with selected process model

Table 1: Comparison of important time response characteristics

\begin{tabular}{lcc}
\hline Tuning techniques & Rise Time & Settling time \\
\hline Ziegler-Nicholas & 143 & 298 \\
Liptak & 16.6 & 257 \\
Shinskey & 137 & 309 \\
Skogestad & 109 & 259 \\
Moros & 18.9 & 297 \\
\hline
\end{tabular}

The performance indices and time response characteristics have been compared to gauge the controller performance. Figure 1 gives the flowchart for organized analysis.

The selected FOPDT process model for heat exchanger can be given as:

$$
G(s)=\frac{e^{-14.7 t}}{1+21.3 s}
$$

Where, process gain $=1$

Dead time $(\theta)=14.7 \mathrm{sec}$

Time constant $=21.3 \mathrm{sec}$

\section{RESULTS AND DISCUSSION}

Various $\mathrm{PI}$ controllers using a number of tuning techniques are designed for the selected
Table 2: Comparison of integral error performance indices

\begin{tabular}{lccc}
\hline Tuning techniques & ISE & IAE & ITAE \\
\hline Ziegler-Nicholas & 34.12 & 64.97 & 4341 \\
Liptak & 22.92 & 42.41 & 2536 \\
Shinskey & 28.17 & 56.73 & 3885 \\
Skogestad & 25.77 & 49 & 2910 \\
Moros & 24.18 & 48.05 & 3238 \\
\hline
\end{tabular}

FOPDT process model. The closed loop step responses and integral error performance indices are calculated for the system. Figure 2 shows the comparison of closed loop step responses of the process for the $\mathrm{PI}$ controller designed using ZieglerNichols, Liptak, Shinskey, skogestad, Moros tuning technique.

Table 1 exhibits the comparison of time response characteristics. The comparison of integral error performance indices viz. IAE, ITAE and ISE are given in Table 2.The minimum rise time and settling time are for the PI controller using Liptak tuning technique, whereas maximum rise time and settling time is obtained using Ziegler Nichols and Shinskey tuning methods respectively. Performance indices are maximum for $\mathrm{PI}$ controllers designed using Ziegler Nichols tuning technique and minimum in case of $\mathrm{PI}$ controller designed with Liptak tuning technique. 


\section{CONCLUSION}

PI controllers have been designed with various tuning techniques, for Heat exchanger process which is modelled as FOPDT process model, to choose one of the best PI controller. For the selected complex industrial process, the $\mathrm{PI}$ controller using Liptak tuning technique gives the best time response characteristics and optimum value of performance indices. Hence the PI controller designed using Liptak tuning technique exhibits the best performance in comparison with all the other $\mathrm{PI}$ controllers in the heat exchanger process.

\section{REFERENCES}

1. Normey-Rico, J. E.; Camacho, E. F.; Control Engineering Practice, 2008, 16, 407-428.

2. García, P; Albertos, P; Journal of Process Control, 2010, 20, 877-884

3. Jangwan, R.; Chaturvedi, M.; Juneja, P.K.; Sunori, S; Singh, P; Proceedings of the International Conference on Advances in Computing, Communications and Informatics, IEEE Xplore, 2014, 712 - 717.

4. Chaturvedi, M; Juneja, P; IEEExplore, ICAES 2013, 2013, 313-315.

5. Chaturvedi, M.; Juneja, P.K.; Chauhaan, P; Proceedings of the International Conference on Advances in Computing, Communications and Informatics, IEEE Xplore, 2014, 853 858.

6. Seborg, D. E.; Edgar, T. F.; Mellichamp, D. A.; Wiley, New York, 2004.
7. Wang $\mathrm{X}, \mathrm{Ye} \mathrm{H}$. In International Conference on Transportation, Mechanical, and Electrical Engineering, IEEE, 2011, 1036-1039

8. Kumar, A.; Garg, K. K.; International Journal for Scientific Research \& Development,2015, 3 (04).

9. Padhy, P. K.; Majhi, S; Computers \& Chemical Engineering, 2006, 30 (5), 790-796.

10. Chidambaram, M.; Hung. J. Ind. Chem., 1994, 22, 37-43.

11. O'Dwyer, A.; Imperial College Press, London, 2003, 57.

12. Shamsuzzoha, M; Lee, M.; Industrial \& Engineering Chemistry Research, 200746(7), 2077-91.

13. Balestrino, A.; Landi, A; Medaglia, M.; Satler, M.; In 14th Mediterranean Conference on Control and Automation, IEEE, 2006, 1-6. 